\title{
Emerging Trends in Peripartum Hysterectomy: A Retrospective Study in a Tertiary Care Center over 2 Years
}

\author{
Swati Sharma ${ }^{1}$, Kamalpreet Kaur ${ }^{2}$, Reena Sood ${ }^{3}$, Madhu Nagpal ${ }^{4}$
}

\begin{abstract}
Introduction: Peripartum hysterectomy $(\mathrm{PH})$ is a lifesaving procedure performed at the time of delivery or in the immediate postpartum period in case of intractable obstetrical hemorrhage unresponsive to other measures. The indication for such procedure is severe uterine hemorrhage that may be due to abnormal placentation, i.e., placenta accreta, uterine atony, uterine rupture, leiomyomas, coagulopathy, or laceration of a uterine vessel not manageable by mere conservative measures.

Materials and methods: This retrospective and analytical study was carried out at the Department of Obstetrics and Gynecology, Sri Guru Ram Das Institute of Medical Sciences and Research, Amritsar (SGRDIMSR, Amritsar), for a period of 2 years from January 2017 to December 2018. All the patients who underwent PH were reviewed. All concerned factors related to emergency and critical care were analyzed.

Results: Out of under study cases, nine PH were conducted, seven being emergency and two elective for placenta accreta. The incidence being $3.53 \%$, main indications were placenta accrete, $n=4$ (44.4\%); atonic PPH, $n=3(33.3 \%)$; rupture uterus, $n=2(22.2 \%)$. Out of these, $n=8(88.8 \%)$ were referred cases and $n=1$ (22.2\%) were elderly gravida, almost all patients went to intensive care unit (ICU), average ICU stay being 10 days. Massive blood transfusion was done in $n=3(33.3 \%)$ patients. Morbidity encountered were sepsis, anemia, bladder injuries and hypertension which were analyzed in this study. There was one mortality of G5P3L3A1 in emergency with placenta covering os in shock with severe anemia where emergency hysterectomy was performed for placenta accreta.

Conclusion: Proper antenatal intrapartum care, early referral, and judicious decision making regarding cesarean section are the potential methods which can be implemented to prevent this catastrophic event. The anticipation of such complication by classifying those patients in the risk group, notifying a multidisciplinary team, and treatment, will greatly improve the final outcome.

Keywords: Intrapartum, Peripartum hysterectomy, Placenta accreta.

AMEl's Current Trends in Diagnosis \& Treatment (2019): 10.5005/jp-journals-10055-0059
\end{abstract}

\section{INTRODUCTION}

Emergency peripartum hysterectomy $(\mathrm{EPH})$ is the removal of the uterus after 20 weeks of gestation for uncontrolled uterine bleeding not responding to conservative measures at the time of delivery or within 24 hours of delivery. It is the most demanding obstetrical surgery performed in very trying circumstances of life-threatening hemorrhage. ${ }^{1}$ It is accompanied by substantial morbidity and mortality and is associated with increased rates of intraoperative and postoperative complications. The mortality of $\mathrm{PH}$ is more than 25 times that of hysterectomy performed outside pregnancy. ${ }^{1}$

The most common indication for EPH is severe uterine hemorrhage which cannot be controlled by conservative measures. ${ }^{2}$ Such hemorrhage may be due to abnormal placentation (e.g., placenta previa and placenta accreta), uterine atony, uterine rupture, leiomyomas, coagulopathy, or laceration of a uterine vessel that is not treatable by conservative measures. ${ }^{2-4}$ The relative frequency of these conditions is variable and is dependent on the patient population and practice patterns. ${ }^{2}$ Hemorrhage continues to be the leading individual cause of maternal death worldwide accounting for $27.1 \%$ of deaths as recently as 2014 . $^{5}$

Abnormal placentation, morbidly adherent placenta, is increasing as the incidence for $\mathrm{PH}$, it is divided into placenta accreta, placenta increta, and placenta percreta based on the layer involved and each case has its own prognosis and management.

With active management of the third stage of labor, better antibiotics and use of prostaglandins and oxytocics, various surgical methods for compression of the uterus like B Lynch sutures, internal iliac artery ligation, and Cho's sutures, the incidence of obstetric hysterectomy has reduced.

\footnotetext{
${ }^{1-4}$ Department of Obstetrics and Gynaecology, Sri Guru Ram Das Institute of Medical Sciences and Research, Amritsar, Punjab, India

Corresponding Author: Kamalpreet Kaur, Department of Obstetrics and Gynaecology, Sri Guru Ram Das Institute of Medical Sciences and Research, Amritsar, Punjab, India, Phone: +91 9915469970, e-mail: kamal.rehal90@gmail.com

How to cite this article: Sharma S, Kaur K, Sood R, et al. Emerging Trends in Peripartum Hysterectomy: A Retrospective Study in a Tertiary Care Center over 2 Years. AMEl's Curr Trends Diagn Treat 2019;3(1):8-12. Source of support: Nil

Conflict of interest: None
}

However, $\mathrm{PH}$ remains the last resort in saving maternal life in critical conditions. The factors responsible for a higher incidence of obstetric hysterectomy in the developing countries are poverty, poor transportation facilities, wrong cultural and religious beliefs, high incidence of unbooked pregnancies, and poorly supervised deliveries. ${ }^{6}$ The incidence is increasing in this era not just because of improperly managed third stage of labor or obstructed labor but most likely because of increasing incidence of cesarean sections. This ultimately increases the incidence of placenta previa and accreta. The incidence and prevalence of hysterectomy varies widely across different geographic settings due to variations in uterine pathology, providers and patient factors, and sociocultural reasons. ${ }^{7-9}$ In literature, EPH varies from 0.3 to 6.2 per 1,000 deliverers. ${ }^{10,11}$ It is associated with significant maternal morbidity and mortality.

(-) The Author(s). 2019 Open Access This article is distributed under the terms of the Creative Commons Attribution 4.0International License (https://creativecommons. org/licenses/by-nc/4.0/), which permits unrestricted use, distribution, and non-commercial reproduction in any medium, provided you give appropriate credit to the original author(s) and the source, provide a link to the Creative Commons license, and indicate if changes were made. The Creative Commons Public Domain Dedication waiver (http://creativecommons.org/publicdomain/zero/1.0/) applies to the data made available in this article, unless otherwise stated. 


\section{Materials and Methods}

\section{Study Design and Population}

It is a retrospective analytic study including all women who had undergone EPH from January 2017 to December 2018, at the Department of Obstetrics and Gynecology, Sri Guru Ram Das Institute of Medical Sciences and Research, Amritsar. All the women who had EPH were identified from the labor ward.

\section{Ethical Approval}

The study protocol was reviewed by the Ethical Committee of the Hospital and was granted ethical clearance.

\section{Methodology}

All surgeries were performed by senior consultants. Medical and pathological records of the patients were reviewed retrospectively. Cases were ascertained via a review of the hospital obstetric database and by also checking operation theatre and pathology records. Antenatal women above 28 weeks of gestation were enrolled in the study.

Hysterectomy was performed shortly (within hours) after delivery. Both medical and surgical modalities were used to control the hemorrhage before hysterectomy. Information obtained from the medical records included demographic details, previous obstetric history, details of the current pregnancy and delivery, postpartum hemorrhage, indications for $\mathrm{PH}$, timing of surgery, intraoperative and postoperative vital monitoring, amount of blood transfusion, amount of fluids transfused, ICU stay, need for ventilation, outcomes of hysterectomy of intraoperative and postoperative complications, length of hospital stay, and neonatal outcomes. Intraoperative events like amount of bleeding, condition of previous scar, adhesions, bladder condition, etc. were assessed and compared with other studies. Maternal mortality and complications such as serious hemorrhagic, neurological, urological, infectious, respiratory, renal, and thromboembolic complications were also noted. The type of cesarean classical or lower segment and the type of surgery subtotal and total were also noted.

\section{Statistical Analysis}

The recorded data were compiled and entered in a spreadsheet computer program (Microsoft Excel 2010) and then exported to a data editor page of SPSS version 19 (SPSS Inc., Chicago, Illinois, USA).

Descriptive statistics included computation of percentages. The statistical tests applied for the analysis were Pearson's Chi-square test $\left(\chi^{2}\right)$ and Fisher exact test. For both the tests, the confidence interval and the $p$ value were set at $95 \%$ and $\leq 0.05$, respectively.

\section{Objective}

The objectives of this study were to estimate the incidence, indications, risk factors, surgical complications and postoperative complications, and maternal outcome associated with $\mathrm{PH}$ in a tertiary referral teaching hospital.

\section{Results}

The overall incidence of $\mathrm{PH}$ was 3.5 per 1,000 deliveries in this study. Table 1 depicts that $44.4 \%$ of cases belong to the age group of $>35$ years, while $33.3 \%$ of cases belong to the age group of 30-35 years, rest $22.2 \%$ were of the age group of 25-29 years. The mean age of cases was $28.4 \pm 3.8$ years. All the cases were multiparous.
Table 2 describes that the majority of cases were referred cases (89\%), and maximum cases had more than 2 lower segment cesarean section (LSCS) (55.6\%).

Table 3 depicts that $89 \%$ of cases were referred to cases in an emergency, while $11 \%$ were antenatally prediagnosed as placenta accreta in our ANC clinic and were taken up electively for the surgery. $67 \%$ of cases had a history of only previous LSCS (lower segment cesarean section), while 33\% of cases had a history previous LSCS as well as dilatation and curettages.

Table 4 shows that main indications for $\mathrm{PH}$ in this study were morbidly adherent placenta (44.4\%), atonic uterus (33.3\%), and rupture uterus (22.2\%). Almost $89 \%$ of cases required urgent intervention and underwent emergency hysterectomy, while one booked; known case of placenta accreta was taken up electively.

Table 5 depicts that the most common complication leading to morbidity was anemia (33.3\%) followed by disseminated intravascular coagulation (DIC) and wound infection (22.2\% each), bladder injuries, and relaprotomy (11.2\% each).

Table 6 shows that morbidly adherent placenta being the main cause and its other types were studied and about $57.8 \%$ cases were placenta accreta, $28.5 \%$ were placenta increta, and $14.2 \%$ placenta percreta.

Table 1: Age group

\begin{tabular}{lll}
\hline Age & Number & Percentage \\
\hline $25-29$ years & 2 & 22.2 \\
$30-35$ years & 3 & 33.3 \\
$>35$ years & 4 & 44.4 \\
Mean \pm SD & & $31.22 \pm 3.49$ \\
\hline
\end{tabular}

Table 2: Booked and previous LSCS status

\begin{tabular}{llc}
\hline & Number & Percentage \\
\hline Booked status & & \\
Booked & 1 & 11.1 \\
$\quad$ Referred & 8 & 88.9 \\
Previous LSCS & & \\
0 & 2 & 22.2 \\
1 & 2 & 22.2 \\
2 & 5 & 55.6 \\
Total & 9 & 100.0 \\
\hline
\end{tabular}

Table 3: Risk factors

\begin{tabular}{llc}
\hline & Number & Percentage \\
\hline Parity & & \\
Multipara & 9 & 100.0 \\
$\quad$ Nullipara & 0 & 0.0 \\
Previous LSCS & & \\
$\quad$ Previous LSCS & 6 & 66.7 \\
$\quad$ Previous abortion/LSCS & 3 & 33.3 \\
Total & 9 & 100.0 \\
\hline
\end{tabular}

Table 4: Indications for EPH

\begin{tabular}{llc}
\hline Risk leading surgery & Number & Percentage \\
\hline Morbidly adherent placenta & 4 & 44.4 \\
Atonic uterus & 3 & 33.3 \\
Rupture uterus & 2 & 22.3 \\
Total & 9 & 100.0 \\
\hline
\end{tabular}


Table 5: Postoperative complications

\begin{tabular}{llc}
\hline Morbidity & Number & Percentage \\
\hline DIC & 2 & 22.2 \\
Anemias & 3 & 33.3 \\
Wound infection & 2 & 22.2 \\
Bladder injuries & 1 & 11.1 \\
Relaprotomy & 1 & 11.1 \\
Total & 9 & 100.0 \\
\hline
\end{tabular}

Table 6: Abnormal placentation

\begin{tabular}{llc}
\hline Morbidly adherent placenta & Frequency & Percentage \\
\hline Placenta accreta & 4 & 57.1 \\
Placenta increta & 2 & 28.5 \\
Placenta percreta & 1 & 14.2 \\
Total & 7 & 100 \\
\hline
\end{tabular}

Table 7: ICU interventions

\begin{tabular}{lll}
\hline ICU intervention & No. of cases & Percentage \\
\hline Mechanical ventilator & 5 & 55.5 \\
Blood products & 8 & 88.9 \\
Inotropes & 6 & 66.6 \\
Dialysis & 1 & 11.1 \\
Massive blood transfusion & 3 & 33.3 \\
Intubation & 4 & 44.4 \\
Central line inserted & 6 & 66.6 \\
\hline
\end{tabular}

Table 8: ICU stay

\begin{tabular}{llc}
\hline ICU stay & Frequency & Percentage \\
\hline$<5$ days & 5 & 55.5 \\
$5-10$ days & 1 & 11.1 \\
$>10$ days & 3 & 33.3 \\
Total & 9 & 100 \\
\hline
\end{tabular}

Table 7 highlights ICU interventions required, all cases required blood transfusion, and massive blood transfusion (BT) was required in $33.3 \%$. Different blood components were transfused and the record was maintained. All the intervention required in ICU were recorded.

Table 8 shows that the ICU stay was required in all the cases, $55.6 \%$ stayed for $1-5$ days, while $22.2 \%$ of cases being critical stayed for $>10$ days.

\section{Discussion}

The incidence of EPH in the present study was $0.35 \%$. This rate is higher to that reported from Columbia ${ }^{12}(0.08 \%)$ and US ${ }^{13}(0.06 \%)$, while the rate is lower to that reported from Nigeria ${ }^{14}(0.51 \%)$ and China ${ }^{15}(0.42 \%)$. The higher rate of EPH in the present study attributed to the facts that our center is a tertiary referral hospital receiving an unbooked rural referral in very deteriorated and late decompensated condition.

It was observed that the majority of the patients (44.4\%) belong to the age group of $>35$ years, while $33.3 \%$ belong to the age group of 30-35 years and rest $22.2 \%$ are of the age group of $25-29$ years. The mean age was $31.22 \pm 3.49$ years with a range of $25-40$ years. The above results were consistent with Agrawal et al. ${ }^{16}$ and Ehtisham et al., ${ }^{17}$ where the mean age in their study was 27.61 years and 31 years, respectively. However, compared to a study in New York by Kastner et al. ${ }^{18}$ and Khanum et al. ${ }^{19}$ where the mean maternal age was 32.3 years and 35 years, respectively.

A high association of multiparity was also seen in the present study with PHs. The maximum number of patients (82.5\%) was multiparous (P2). High parity is associated with an increased risk of ruptured uterus. Similar findings were also reported by Imudia et al., ${ }^{20}$ Zelop et al., ${ }^{21}$ and Chawla et al. ${ }^{22}$

The incidence of $\mathrm{PH}$ occurring with a history of previous cesarean section has increased significantly over the last few decades. In our study, all 9 (100\%) women had a history of previous cesarean section, and, out of these, $77.8 \%$ had $\geq 2$ LSCS. These findings were consistent with findings in recent literature, with a history of previous cesarean section ranging from $18.8 \%$ to $60.5 \% .{ }^{23}$ Similarly, Agrawal et al. ${ }^{16}$ identified $44.44 \%$ of patients in their study who had a history of either one or two previous cesarean sections. Knight et al. ${ }^{23}$ also stated that prior cesarean delivery leads to a greater than seven times increase in the odds of having a $\mathrm{PH}$ to control hemorrhage. The risk associated with cesarean section extends beyond the initial cesarean delivery into the subsequent deliveries. A prior cesarean delivery results in uterine scarring resulting in an increased risk of abnormal placentation, including placenta previa and placenta accreta in subsequent pregnancies. It also increases the risk for future abdominal deliveries and uterine rupture.

In our study, $67 \%$ of cases had a history of only previous LSC, while $33 \%$ of cases had a history of previous LSCS as well as curettages. Zahn and Yeomans ${ }^{24}$ also listed a history of curettage as risk factors associated with placenta accreta. Ananth et al. ${ }^{25}$ found a strong association between a history of abortion and the subsequent development of placenta previa.

The most common indications of EPH in the present study were morbidly adherent placenta (44.4\%) followed by atonic uterus (33.3\%) and rupture uterus (22.2\%). But a higher rate of EPH for ruptured uterus was reported by Archana et al. ${ }^{26}$ (75\%) and Ohonsi and Olayinka ${ }^{27}$ (73\%). On the contrary, a study from $\mathrm{UK}^{28}$ reported only $8 \%$ of EPH for the same indication. Owing to ignorance, illiteracy, unbooked status, and poor socioeconomic status, parturients with high-risk pregnancies get only a formal and improper supervision antepartum specially intrapartum at the periphery and delayed referral results in poor outcome.

The atonic uterus was contributing $33.3 \%$ to EPH. Similarly, Chawla et al. ${ }^{22}$ reported atony (25\%) as a leading cause for EPH. Contrary to this, Ohonsi and Olayinka, ${ }^{27}$ Singh and Nagrath, ${ }^{29}$ and Nazam et al. ${ }^{30}$ reported the frequency of $6.7 \%, 15.6 \%$, and $16.6 \%$ for the same, respectively. Better management of the third stage of labor (AMTSL) with strong effective uterotonic drugs available at periphery might be the cause for lesser incidence of the atonic uterus and referrals for the same. Recent advances in medical and conservative surgical measures like efficient uterotonic, compression of the uterus, uterine catheters and stepwise devascularization of the uterus help to save uterus after postpartum hemorrhage. Morbidly adherent placenta was seen in only $22.2 \%$. Chawla et al. ${ }^{22}$ reported $21 \%$ their series. Ohonsi and Olayinka ${ }^{27}$ observed $13.3 \%$ and $6.7 \%$ incidences of the same for EPH. This is in contrast to the study of $\mathrm{UK}^{27}$ in which $38 \%$ of cases of EPH were for the indication of morbidly adherent placenta. The prominence of this indication for EPH has been reported globally attributed by increasing cesarean rates. 
In this study, all the patients required blood transfusion, while massive blood transfusion was required in $33.3 \%$ of cases; all the cases went to ICU, while $33.3 \%$ of cases required to stay for more than 10 days. All the interventions done in ICU were noted and studied, complications were studied in detail, and both recurrent and residual problems were discussed.

The mortality rate following EPH in various studies conducted worldwide is variable, ranging from 4 to $4.5 \%$ to as high as $23.8 \%$. $^{31-34}$ In the present study, the most common complication leading to morbidity was anemia (33.3\%) followed by DIC and wound infection ( $22.2 \%$ each), bladder injuries, and relaprotomy (11.2\% each). This might have occurred mainly because of the need for multiple blood transfusions which may induce sepsis, coagulopathy, inadvertent bladder injury, and acute renal failure. ${ }^{31}$ Bladder injuries occurred mainly due to scarring and adhesions in vesicouterine space that develop following previous cesarean delivery.

\section{Conclusion}

Our study concluded that the higher incidence of $\mathrm{PH}$ is because of the higher prevalence of risk factors like multiparity, previous cesarean section, placenta previa, and current cesarean delivery. Most common indications for $\mathrm{PH}$ were abnormal placentation, rupture uterus, and atonic uterus. To overcome these factors, adequately equipped antenatal care, early identification of risk factors, hospital delivery facilities, and timely intervention by an obstetrician to carry out medical/conservative surgical treatments of primary postpartum hemorrhage are needed to reduce the incidence of EPH and morbidity associated with it. The main cause of $\mathrm{PH}$ being an increase in the number of primary cesareans; therefore, attempt should be made to reduce the rate of primary C-sections, CDMR should not be encouraged at any cost and patient needs to be counseled about complications and after-effects of it. $\mathrm{PH}$ is the most challenging surgery; therefore, multidisciplinary approach is adopted in all the cases for better outcomes. Need for blood transfusion, intensive care, associated risk of trauma to the bladder, and ureter make this one of the markers of severe maternal morbidity and potential near-miss mortality in both developed and developing countries.

This study opens new vista for more detailed analysis and audit, more meticulous training to all faculty member for senior residents level above, more intensive laboring attitude to junior residents to identify the role failure, suspect a problem, complete the checklist for $\mathrm{EPH}$, proper postoperative care, and vigilant ICU management and also to the neonatologist to give care to the survivor baby born after the uterus has been sacrificed.

\section{References}

1. Wise A, Clark V. Challenges of major obstetric hemorrhage. Best Pract Res Clin Obstet Gynaecol 2010;24:353-365. DOI: 10.1016/ j.bpobgyn.2009.11.011.

2. Shellhas CS, Gilbert $S$, et al. Eunice kennedy shriver national institutes of health and human development maternal-fetal medicine units network. The frequency and complication rates of hysterectomy accompanying cesarean delivery. Obstet Gynecol 2009;114(2): 224-229. DOI: 10.1097/AOG.0b013e3181ad9442.

3. Zwart JJ, Dijk PD, et al. Peripartum hysterectomy and arterial embolization for major obstetric hemorrhage: a 2-year nationwide cohort study in the Netherlands. Am J Obstet Gynecol 2010;202:150. DOI: 10.1016/j.ajog.2009.09.003.

4. Rachaga S, Sivanesaratnam V. Caesarean hysterectomy-a review of 21 cases in the University Hospital, Kuala Lumpur. Eur J Obstet Gynecol Reprod Biol 1984;16:321-326. DOI: 10.1016/0028-2243(84)90160-6.
5. Say L, Chou D, et al. Global causes of maternal death: a WHO systematic analysis. Lancet Glob Health 2014;2(6):e323-e333. DOI: 10.1016/S2214-109X(14)70227-X.

6. Wright JD, Devine $P$, et al. Morbidity and mortality of peripartum hysterectomy. Obstet Gynecol 2010;115:1187. DOI: 10.1097/ AOG.0b013e3181df94fb.

7. Stankiewicz A, Pogany L, et al. Prevalence of self-reported hysterectomy among Canadian women, 2000/2001-2008. Chronic Dis Inj Can 2014;34(1):30-35.

8. Coulter A, McPherson K, et al. Do British women undergo too many or too few hysterectomies? Soc Sci Med 1988;27(9):987-994. DOI: 10.1016/0277-9536(88)90289-4.

9. Desai S, Campbell OM, et al. Incidence and determinants of hysterectomy in a low-income setting in Gujarat, India. Health Policy Plan 2017;32(1):68-68. DOI: 10.1093/heapol/czw099.

10. Machqdo LSM. Emergency peripartum hysterectomy: incidence, indications, risks factors and outcome. N Am J Med Sci 2011;3:358-361. DOI: 10.4297/najms.2011.358.

11. Obiechina NJ, Eleje GU, et al. Emergency peripartum hysterectomy in Nnewi, Nigeria: A 10-years review. Nigar J Clin Pract 2012;15:168-171. DOI: $10.4103 / 1119-3077.97303$.

12. Owolabi MS, Blake RE, et al. Incidence and determinants of peripartum hysterectomy in the metropolitan area of the District of Columbia. J Reprod Med 2013;58(3-4):167-172.

13. Bodelon C, Bernabe-Ortiz A, et al. Factors associated with peripartum hysterectomy. Obstet Gynecol 2009;114(1):115-123. DOI: 10.1097/ AOG.0b013e3181a81cdd.

14. Nwobodo E, Nnadi D. Emergency obstetric hysterectomy in a tertiary hospital in sokoto, Nigeria. Ann Med Health Sci Res 2012;2(1):37-40. DOI: $10.4103 / 2141-9248.96935$.

15. Pradhan M, Yong S. Emergency peripartum hysterectomy as postpartum hemorrhage treatment: incidence, risk factors, and complications. J Nepal Med Assoc 2014;52(193):668-676. DOI: 10.31729/jnma.2375.

16. Agrawal $S$, Yadav $R$, et al. Peripartum hysterectomy in a teaching hospital in India. Asian J Med Sci 2013;4(1):34-36. DOI: 10.3126/ajms. v4i1.6967.

17. Ehtisham S. Emergency peripartum hysterectomy. Pak J Surg 2011;27(4):288-291.

18. Kastner ES, Figueroa R, et al. Emergency peripartum hysterectomy: Experience at a community teaching hospital. J Obstet Gynecol 2002;99:971-975. DOI: 10.1097/00006250-200206000-00003.

19. Khanum F, Sadaf R, et al. Emergency peripartum hysterectomy in a Tertiary Care Hospital. J Med Sci 2013;21(2):58-61. DOI: 10.1007/ s13224-013-0423-1.

20. Imudia AN, Awonuga AO, et al. Incidence, trends, risk factors, indications for and complication associated with cesarean hysterectomy: a 17 year experience from a single instution. Arc Obstet Gynecol 2009;280(4):619-623. DOI: 10.1007/s00404-009-0984-5.

21. Zelop CM, Harlow BL, et al. Emergency peripartum hysterectomy. Am J Obstet Gynecol 1993;168:1443-1448. DOI: 10.1016/S00029378(11)90779-0.

22. Chawla J, Arora C, et al. Emergency obstetric hysterectomy: a retrospective study from teaching Hospital in North India over Eight Years. Oman Med J 2015;30(3):181-186. DOI: 10.5001/omj. 2015.39.

23. Knight M, Kurinczuk JJ, et al. Cesarean deliveryand peripartum hysterectomy. J Obstet Gynecol 2008;111:97-105. DOI: 10.1097/01. AOG.0000296658.83240.6d.

24. Zahn CM, Yeomans ER. Postpartum hemorrhage: Placenta accretas, uterine inversion, and puerperal hematomas. Clin Obstet Gynecol 1990;33:422-431. DOI: 10.1097/00003081-199009000-00006.

25. Ananth CV, Smulian JC, et al. The association of placenta previa with history of cesarean delivery and abortion. A meta-analysis. Am J Obset Gynecol 1997;177:1071-1078. DOI: 10.1016/S00029378(97)70017-6.

26. Archana K, Sahay PB. A clinical review of emergency obstetric hysterectomy. J Obstet Gynaecol India 2009;59:427-431. 
27. Omole-Ohonsi A, Taiwo Olayinka H. Emergency peripartum hysterectomy in a developing country. J Obstet Gynaecol Can 2012;34(10):954-960. DOI: 10.1016/S1701-2163(16)35409-3.

28. Knight M. UKOSS. Peripartum Hysterectomy in the UK: management and outcomes of the associated hemorrhage. BJOG 2007;114(11): 1380-1387. DOI: 10.1111/j.1471-0528.2007.01507.x.

29. Singh R, Nagrath A. Emergency obstetric hysterectomy-a retrospective study of 54 cases over a period of 5 years. J Obstet Gyneco India 2005;55:428-430.

30. Nazam R, Bansal P, et al. Emergency obstetrics hysterectomy: a retrospective study at a Tertiary Care Hospital. J Clin Diagn Res 2010;4:2864-2868.
31. Kwee $\mathrm{A}$, Boto $\mathrm{ML}$, et al. Emergency peripartum hysterectomy. a prospective study in The Netherlands. Eur J Obstet Gynecol Reprod Biol 2006;124:187-192. DOI: 10.1016/j.ejogrb.2005.06.012.

32. Zorlu CG, Turan C, et al. Emergency hysterectomy in modern obstetric practice: changing clinical perspective in time. Acta Obstet Gynecol Scand 1998;77:186-190.

33. Hamsho MA, Alsakka M. Emergency obstetric hysterectomy in Qatar-a 20-year review. Int J Fertil Women's Medicine 1999;44(4): 209-211.

34. Umezurike CC, Feyi-Waboso PA, et al. Peripartum hysterectomy in Aba southeastern Nigeria. Australian New Zealand. J Obstet Gynaecol 2008 Dec 1;48(6):580-582. 